\title{
Isothiouronium Salts Based on Anthracene and Pyrene as Anion Sensors ${ }^{\dagger}$
}

\author{
Quynh Pham Bao Nguyen and Taek Hyeon Kim* \\ Department of Applied Chemistry and Center for Functional Nano Fine Chemicals, Chonnam National University, \\ Gwangju 500-757, Korea. *E-mail: thkim@chonnam.ac.kr \\ Received November 6, 2009, Accepted December 29, 2009
}

Key Words: Isothiouronium salts, Isomerism, Anion sensing

Organic sensors have attracted much attention due to their many possible applications in analytical and biomedical research. Therefore, a variety of synthetic receptors for anions have been reported. ${ }^{1}$ Among them, thiourea receptors have been thoroughly exploited in the field of molecular recognition, due to their binding of anions through hydrogen bonding. ${ }^{2}$ The use of isothiouronium groups has not been explored very much in the area of anion binding. Such groups can enhance the acidity of the NH moieties, thereby functioning as a better binder compared to the thiourea group. ${ }^{3}$ However, in some cases, the investigation of the anion sensing properties of isothiouronium receptors was complicated by the presence of isomerism. In a previous report, the isomerism of anthracene-isothiouronium salts was detected at room temperature. ${ }^{4}$ Herein, we wish to report the isomerism of different isothiouronium structures, viz. anthracene-bisisothiouronium and pyrene-isothiouronium salts. The anion sensing properties of these structures was also examined.

\section{Results and Discussion}

Isomerism in the isothiouronium salts. The new fluorescent chemosensors 5 and 9 based on anthracene and pyrene, respectively, as fluorescent signals and isothiouronium as a sensing unit were first prepared by refluxing the corresponding thioureas 4 and 8 with benzyl bromide in ethanol (Schemes 1 and 2). During their spectroscopic characterization, the ${ }^{1} \mathrm{HNMR}$ spectra of $\mathbf{5}$ and $\mathbf{9}$ showed two sets of peaks for the protons, thus indicating the existence of two different isomers at ratios of $1: 1$ and $3: 2$, respectively (Figure 1 and Experimental section).

It is well known that isomerism can occur in isothiouronium salts by three possible mechanisms, viz. the oscillation of the carbon-nitrogen double bond, the hindered rotation at the $\mathrm{C}=\mathrm{N}$ bond and the restricted rotation at the $\mathrm{C}=\mathrm{S}$ bond. ${ }^{4}$ The main reason for the isomerism became clearer when the symmetric structure of the isothiouronium salt was examined. It was noted that the two isomers detected at room temperature might result from the syn-anti isomerism, due to the restricted rotation at the $\mathrm{C}=\mathrm{S}$ bond. Therefore, the two sets of peaks of $(4.68,4.40)$ and $(4.51,4.60) \mathrm{ppm}$ at the ratio of $1: 1$ and $3: 2$ were observed for compounds 5 and $\mathbf{9}$, respectively.

As shown in Figure 1, the isothiouronium salts derived from benzene $^{3 \mathrm{f}}$ and naphthalene ${ }^{3 \mathrm{a}}$ have a single form and no isomerism at room temperature (structures I and II, respectively).<smiles>ClCc1c2ccccc2c(CCl)c2ccccc12</smiles>

1

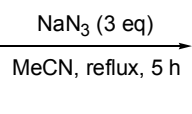

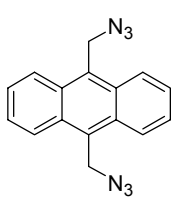

2, not purify, $>99 \%$

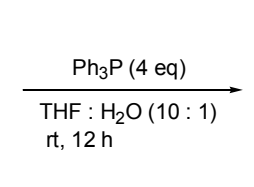

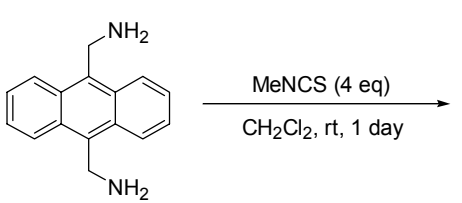

$3,63 \%$

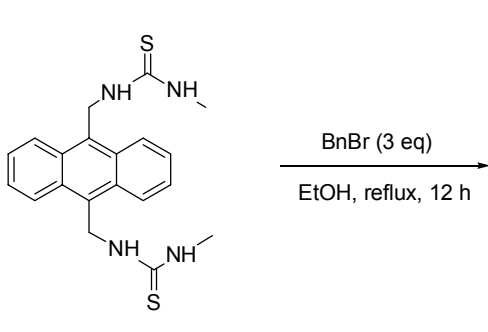

$4,87 \%$

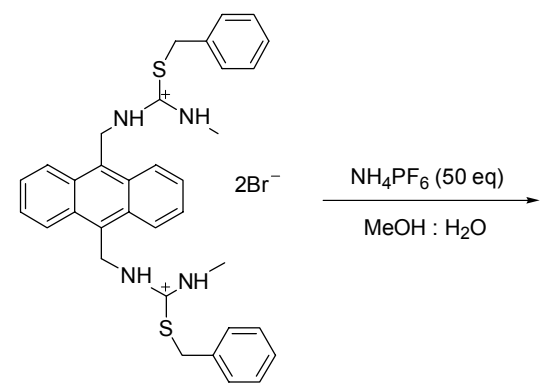

$5,61 \%$

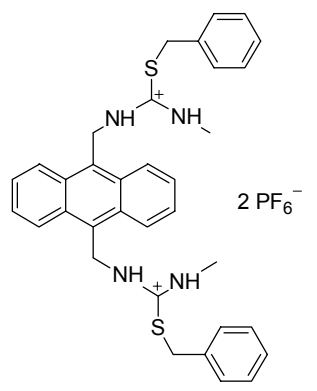

6, $85 \%$

Scheme 1. Synthesis of anthracene-bisisothiouronium 6 


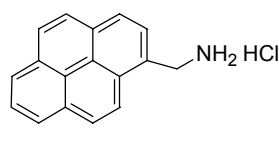

7

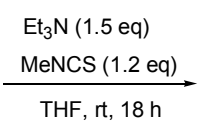

$\frac{\mathrm{NH}_{4} \mathrm{PF}_{6}(50 \mathrm{eq})}{\mathrm{MeOH}: \mathrm{H}_{2} \mathrm{O}: \text { Acetone }}$

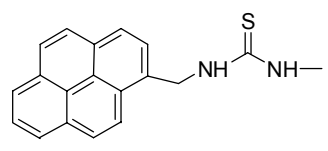

$\underset{\mathrm{EtOH}, \text { reflux, } 20 \mathrm{~h}}{\stackrel{\mathrm{BnBr}(1.1 \mathrm{eq})}{\longrightarrow}}$

$8,88 \%$

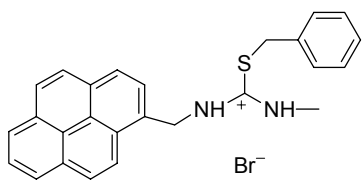

$9,60 \%$

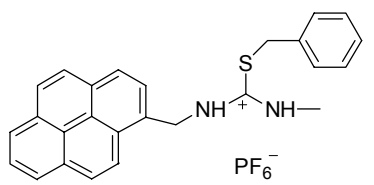

$10,80 \%$

Scheme 2. Synthesis of pyrene-isothiouronium 10
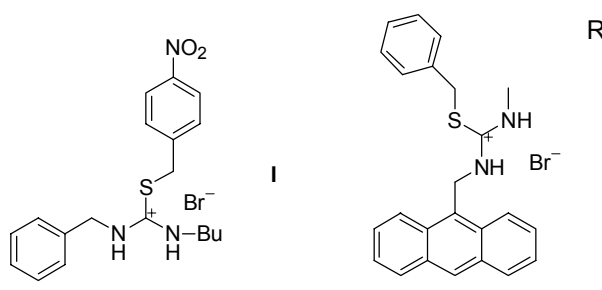

Ratio of two isomers in DMSO- $d_{6}$
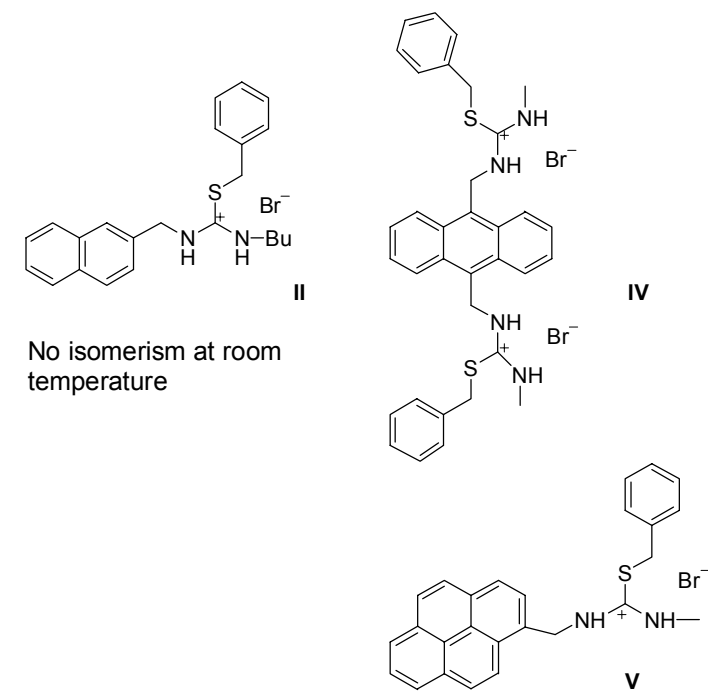

Isomerism at room temperature

Figure 1. Isomerism in several structures of isothiouronium salts.

However, structures III, IV and V based on anthracene and pyrene showed the two isomers which were detected by ${ }^{1} \mathrm{H}$ NMR spectrometry at room temperature. As mentioned above, the restricted rotation at the $\mathrm{C}=\mathrm{S}$ bond caused the isomerism in the isothiouronium salts. It could be hypothesized that the barriers to rotation at the $\mathrm{C}=\mathrm{S}$ bond resulted from the steric hindrance and aromatic-aromatic interaction between the anthracene and pyrene moieties and the S-benzyl group of the isothiouronium salts. More steric hindrance and aromatic-aromatic interactions occurred in structures III, IV, and V as compared to structures I and II. This means that the barrier to rotation at the $\mathrm{C}=\mathrm{S}$ bond was higher in the first case and, thus, that isomerism was detected at room temperature only in the isothiouronium salts based on anthracene and pyrene.

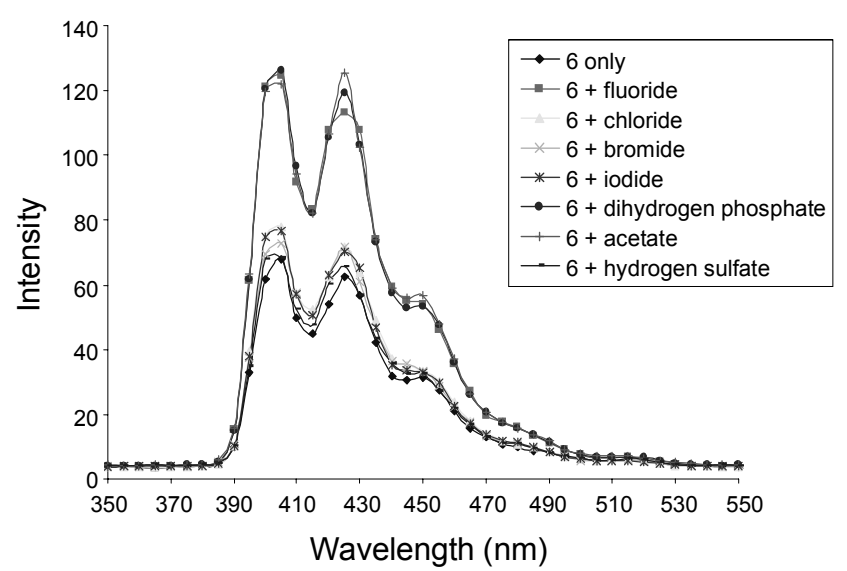

Figure 2. Fluorescent emission changes of $6\left(10^{-6} \mathrm{M}\right)$ upon the addition of the tetrabutylammonium salts of $\mathrm{F}^{-}, \mathrm{Cl}^{-}, \mathrm{Br}^{-}, \mathrm{I}^{-}, \mathrm{H}_{2} \mathrm{PO}_{4}^{-}, \mathrm{OAc}^{-}$, and $\mathrm{HSO}_{4}^{-}$(9 equiv) in acetonitrile : water $(95: 5 \mathrm{v} / \mathrm{v})$ at an excitation wavelength of $260 \mathrm{~nm}$.

Application of anthracene-bisisothiouronium 6 and pyreneisothiuoronium 10 salts for anion sensing. The anion binding abilities of $\mathbf{6}$ and $\mathbf{1 0}$ were first examined in a variety of solvents such as $\mathrm{CHCl}_{3}, \mathrm{MeOH}$, DMSO, $\mathrm{CH}_{3} \mathrm{CN}$, acetone, THF and a mixture of $\mathrm{CH}_{3} \mathrm{CN}: \mathrm{H}_{2} \mathrm{O}(95: 5 \mathrm{v} / \mathrm{v})$. While acetone was a good solvent for the host-guest binding in pyrene-thiourea, ${ }^{2 \mathrm{f}}$ it was totally unsuitable for the similar structure based on pyreneisothiouronium, compound $\mathbf{1 0}$. The fluorescent intensity of $\mathbf{1 0}$ was low and showed little change upon the addition of the fluoride anion in acetone. Acetonitrile was the best solvent for the binding of the isothiouronium salts and anions in fluorescent spectrometry. A mixture of 5\% water in acetonitrile also resulted in a good fluorescent intensity change upon the addition of the anions. As reported, thiourea based sensors ${ }^{2}$ only work in a nonaqueous medium. However, they can work well in an aqueous medium by converting them into isothiouronium sensors, in which both hydrogen bonding and electrostatic interactions are used for anion binding. This finding provides the basis for an important approach to the investigation of water-soluble anion sensors in analytical chemistry. As we have known, a fluorescent anion sensor for use in aqueous solution must meet two requirements. One is sufficiently strong affinity for anions in water, and the other is the ability to convert anion recognition into a fluorescence signal. Most known anion sensors do not 


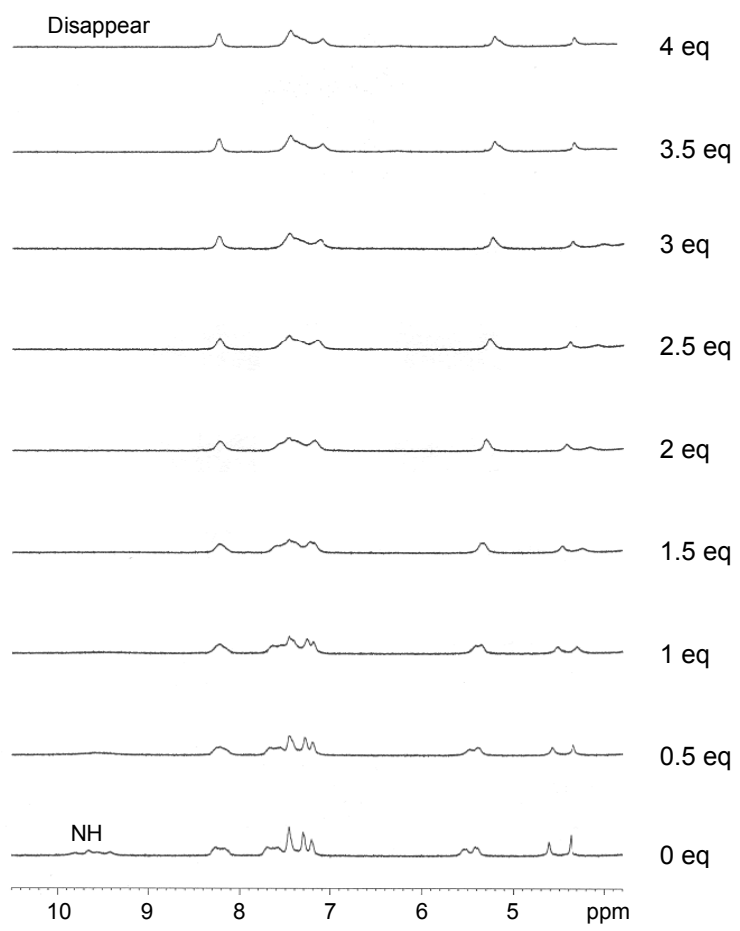

Figure 3. ${ }^{1} \mathrm{H} N \mathrm{NR}$ titration of $6\left(5 \times 10^{-3} \mathrm{M}\right)$ with fluoride in DMSO- $d_{6}$.

have a sufficiently strong affinity for anions in water although they satisfy the latter requirement.

The binding affinities of hosts $\mathbf{6}$ and $\mathbf{1 0}$ for various anions, viz. $\mathrm{F}^{-}, \mathrm{Cl}^{-}, \mathrm{Br}^{-}, \mathrm{I}^{-}, \mathrm{H}_{2} \mathrm{PO}_{4}^{-}, \mathrm{OAc}^{-}$, and $\mathrm{HSO}_{4}{ }^{-}$, were examined in a mixture of acetonitrile and water $(95: 5 \mathrm{v} / \mathrm{v})$ (Figures 2 and 4). In all cases, the fluorescence intensities of $\mathbf{6}$ and $\mathbf{1 0}$ increased significantly upon the addition of $\mathrm{F}, \mathrm{OAc}{ }^{-}$and $\mathrm{H}_{2} \mathrm{PO}_{4}{ }^{-}$ due to the photo-induced electron transfer (PET) processes and changed slightly upon the addition of the other anions. In contrast, while pyrene-thiouronium showed the quenching of the fluorescence intensity upon the addition of the anions, ${ }^{2 f}$ pyrene-isothiouronium showed an increase in its fluorescence intensity, probably because the effect of the electrostatic interaction was much higher than that of the hydrogen bonding in the binding of the host and guest. The fluorescent titration of host 10 and anion fluoride was also examined and the results are shown in Figure 5. However, due to the existence of two isomers in hosts $\mathbf{6}$ and 10, the determination of the binding constant by the fluorescence spectrometry method was quite complicated. $^{5}$

To understand the mechanism underlying the association between hosts $\mathbf{6}$ and $\mathbf{1 0}$ and the fluoride anion, the NMR titration method in DMSO- $d_{6}$ was employed. As shown in Figures 3 and 6 , the $\mathrm{NH}$ protons of the thiouronium moieties of hosts $\mathbf{6}$ and $\mathbf{1 0}$ disappeared upon the addition of fluoride, indicating the formation of hydrogen bonding, while the other protons tended to shift slightly toward the upfield region. Interestingly, for host 6, by monitoring of the peaks at 4.38 and $4.62 \mathrm{ppm}$ upon the addition of fluoride anion (Figure 3 ), we can see that these peaks tended to shift slightly toward the upfield region at the first time and then the peak at 4.38 ppm disappeared gradu-

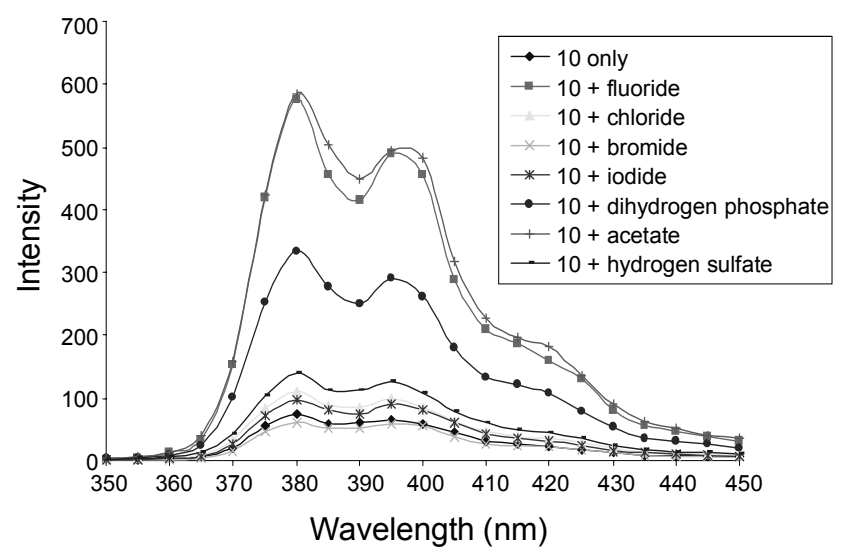

Figure 4. Fluorescent emission changes of $10\left(10^{-5} \mathrm{M}\right)$ upon the addition of the tetrabutylammonium salts of $\mathrm{F}^{-}, \mathrm{Cl}^{-}, \mathrm{Br}^{-}, \mathrm{I}^{-}, \mathrm{H}_{2} \mathrm{PO}_{4}^{-}, \mathrm{OAc}^{-}$, and $\mathrm{HSO}_{4}{ }^{-}$(9 equiv) in acetonitrile : water $(95: 5 \mathrm{v} / \mathrm{v})$ at an excitation wavelength of $275 \mathrm{~nm}$.

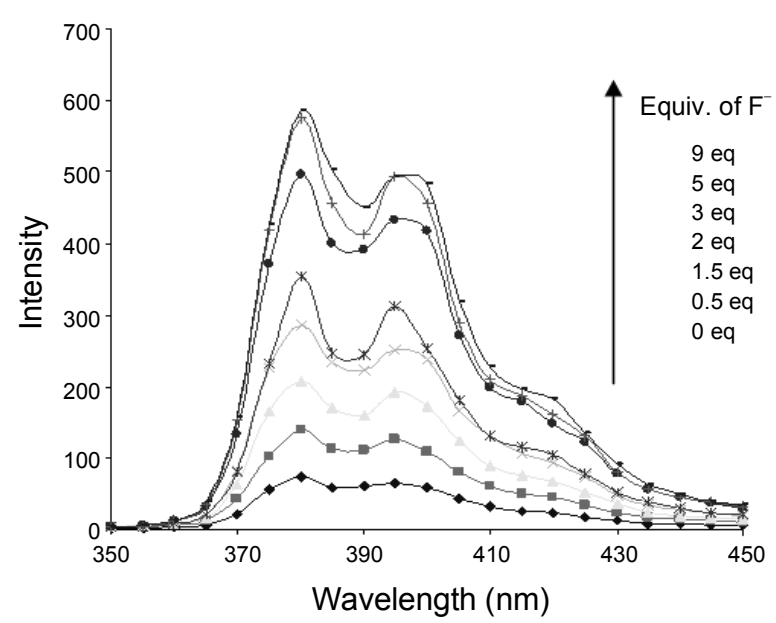

Figure 5. The changes in the emission spectra of $10\left(10^{-5} \mathrm{M}\right)$ upon the addition of different fluoride concentrations in acetonitrile : water $(95: 5 \mathrm{v} / \mathrm{v})$ at an excitation wavelength of $275 \mathrm{~nm}$.

ally and upon adding over three equivalents of fluoride to the host, the peaks of the two conformers tended to merge into one another. This means that some degree of conversion took place between the two isomers during the binding. Judging from the titration results, we can conclude that the two isomers of host 6 bound the fluoride anion in equilibrium. In contrast, for host $\mathbf{1 0}$, the peaks at 4.49 and 4.59 ppm shifted together toward the upfield region. That means the two isomers of host $\mathbf{1 0}$ bound the fluoride anion in parallel.

\section{Conclusions}

In summary, we prepared anthracene-bisisothiouronium and pyrene-isothiouronium salts as anion chemosensors, which showed significant fluorescence enhancement upon the addition of fluoride, acetate and dihydrogen phosphate, even in an aqueous medium. Due to the isomerism that occurred, the two isomers of the anthracene-bisisothiouronium salt bound the fluoride anion in equilibrium, while the two isomers of the pyreneisothiouronium salt bound the fluoride anion in parallel. 


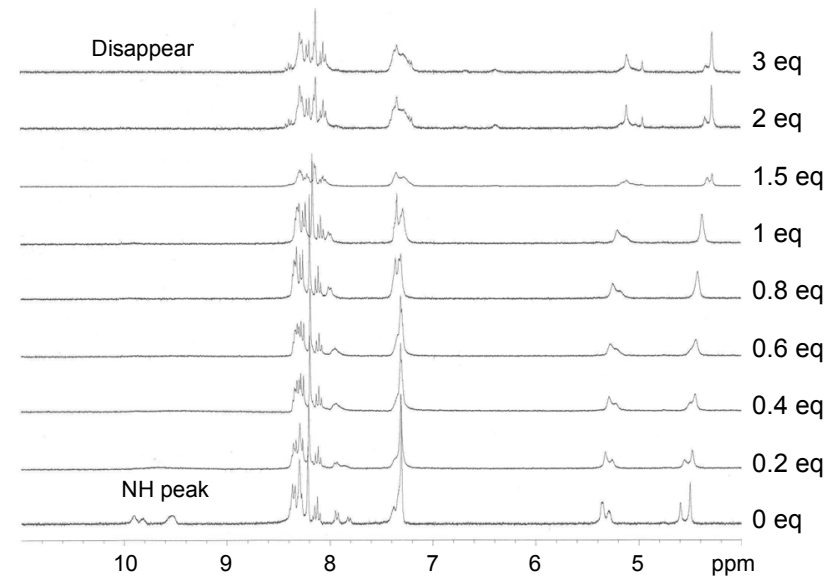

Figure 6. ${ }^{1} \mathrm{H}$ NMR titration of $\mathbf{1 0}\left(5 \times 10^{-3} \mathrm{M}\right)$ with fluoride in DMSO- $d_{6}$.

\section{Experimental Section}

Typical procedure for the synthesis of the isothiouronium salts. The thiourea compounds $\mathbf{4}$ or $\mathbf{8}$ were dissolved in absolute ethanol and heated to reflux under an inert atmosphere of argon. Then, benzyl bromide ( 3 or 1.1 eq.) was added dropwise. The reaction mixture was stirred overnight. The solvent was removed by evaporation and the organic products were purified by precipitation in methanol and diethyl ether or methanol and $n$-hexane to yield the pure powder compounds 5 or 9 .

9,10-Bis [( $S$-benzyl- $N$ '-methyl- $N$-isothiouronio) methyl] anthracene bromide (5): The ${ }^{1} \mathrm{H}$ NMR spectrum of compound $\mathbf{5}$ $(61 \%)$ contains two sets of peaks for the two isomers, $a$ and $b$, in DMSO- $d_{6}$ at a ratio of $1: 1 . \mathrm{mp} 198-200{ }^{\circ} \mathrm{C}$. ${ }^{1} \mathrm{H} \mathrm{NMR}(300$ $\left.\mathrm{MHz}, \mathrm{DMSO}-d_{6}\right) \delta$ 9.43-9.88 (4H, b), 7.23-8.28 (18H, m), 5.52 $(4 \mathrm{H}, \mathrm{m}), 4.68(2 \mathrm{H}, \mathrm{s}), 4.40(2 \mathrm{H}, \mathrm{s}), 3.18(3 \mathrm{H}, \mathrm{s}), 2.78(3 \mathrm{H}, \mathrm{s})$. ESI-Mass (positive mode) $\left[\mathrm{M}^{2+} . \mathrm{H}^{-}\right]$562.9. ESI-Mass (negative mode) $\left[\mathrm{M}^{2+} .2 \mathrm{Br}^{-} . \mathrm{H}^{-}\right] 722.9$.

1-[( $S$-Benzyl- $N$ '-methyl- $N$-isothiouronio $)$ methyl $]$ pyrene bromide (9): The ${ }^{1} \mathrm{H}$ NMR spectrum of compound 9 (60\%) contains two sets of peaks for the two isomers, a and b, in DMSO- $d_{6}$ at a ratio of $3: 2 . \mathrm{mp} 189-190{ }^{\circ} \mathrm{C}$. For isomer a, ${ }^{1} \mathrm{H}$ NMR (300 MHz, DMSO- $\left.d_{6}\right) \delta$ 9.50-9.90 (2H, b), 7.27-8.35 (14H, m) 5.34 $(2 \mathrm{H}, \mathrm{s}), 4.51(2 \mathrm{H}, \mathrm{s}), 3.04(3 \mathrm{H}, \mathrm{s})$. For isomer $\mathrm{b},{ }^{1} \mathrm{H}$ NMR $(300$ MHz, DMSO- $\left.d_{6}\right) \delta$ 9.50-9.90 (2H, b), 7.27-8.35 (14H, m) 5.29 $(2 \mathrm{H}, \mathrm{s}), 4.60(2 \mathrm{H}, \mathrm{s}), 3.04(3 \mathrm{H}, \mathrm{s})$. ESI-Mass (positive mode) $\left[\mathrm{M}^{+}\right]$394.9. ESI-Mass (negative mode) $\left[\mathrm{M}^{+} .2 \mathrm{Br}^{-}\right] 554.9$.

Typical procedure for the synthesis of the hexafluorophosphate salts. The bromide salts $\mathbf{5}$ and $\mathbf{9}$ were dissolved in $\mathrm{MeOH}$. During the dropwise addition of aqueous $\mathrm{NH}_{4} \mathrm{PF}_{6}$ solution (50 eq.), precipitates were formed. After washing the precipitates several times with water, the desire products $\mathbf{6}$ and $\mathbf{1 0}$ were obtained as pure compounds.

9,10-Bis [( $S$-benzyl- $N$ '-methyl- $N$-isothiouronio $)$ methyl] anthracene hexafluorophosphate (6): The ${ }^{1} \mathrm{H}$ NMR spectrum of compound $6(85 \%)$ contains two sets of peaks for the two isomers, $a$ and $b$, in DMSO- $d_{6}$ at a ratio of $5: 4 \cdot \operatorname{mp} 99-100{ }^{\circ} \mathrm{C}$. For isomer a, ${ }^{1} \mathrm{H}$ NMR $\left(300 \mathrm{MHz}, \mathrm{DMSO}-d_{6}\right) \delta 9.40-9.75(2 \mathrm{H}$, b), 7.22-8.26 (9H, m), $5.42(2 \mathrm{H}, \mathrm{d}, J=8.91 \mathrm{~Hz}), 4.38(2 \mathrm{H}, \mathrm{s})$,
$3.18(3 \mathrm{H}, \mathrm{s})$. For isomer b, ${ }^{1} \mathrm{H}$ NMR $\left(300 \mathrm{MHz}, \mathrm{DMSO}-d_{6}\right) \delta$ 9.40-9.75 (2H, b), 7.22-8.26 (9H, m), $5.54(2 \mathrm{H}, \mathrm{d}, J=8.91 \mathrm{~Hz})$, $4.62(2 \mathrm{H}, \mathrm{s}), 2.77(3 \mathrm{H}, \mathrm{s})$. ESI-Mass (positive mode) $\left[\mathrm{M}^{2+} . \mathrm{H}^{-}\right]$ 562.9. ESI-Mass (negative mode) $\left[\mathrm{M}^{2+} .2 \mathrm{PF}_{6}^{-} . \mathrm{H}^{-}\right] 854.1$.

1-[(S-Benzyl- $N$ '-methyl- $N$-isothiouronio)methyl]pyrene hexafluorophosphate (10): The ${ }^{1} \mathrm{H}$ NMR spectrum of compound $10(80 \%)$ contains two sets of peaks for the two isomers, a and $\mathrm{b}$, in DMSO- $d_{6}$ at a ratio of $3: 2 . \mathrm{mp} 109-110^{\circ} \mathrm{C}$. For isomer a, ${ }^{1} \mathrm{H}$ NMR (300 MHz, DMSO- $\left.d_{6}\right) \delta$ 9.40-9.90 (2H, b), 7.29-8.35 $(14 \mathrm{H}, \mathrm{m}) 5.34(2 \mathrm{H}, \mathrm{s}), 4.49(2 \mathrm{H}, \mathrm{s}), 3.04(3 \mathrm{H}, \mathrm{s})$. For isomer b, ${ }^{1} \mathrm{H}$ NMR $\left(300 \mathrm{MHz}, \mathrm{DMSO}-d_{6}\right) \delta$ 9.40-9.90 (2H, b), 7.29-8.35 $(14 \mathrm{H}, \mathrm{m}) 5.27(2 \mathrm{H}, \mathrm{s}), 4.59(2 \mathrm{H}, \mathrm{s}), 3.04(3 \mathrm{H}, \mathrm{s})$. ESI-Mass (positive mode) $\left[\mathrm{M}^{+}\right]$394.9. ESI-Mass (negative mode) $\left[\mathrm{M}^{+} .2 \mathrm{PF}_{6}^{-}\right]$ 685.0 .

Acknowledgments. This work was supported by the National Research Foundation of Korea Grant funded by the Korean Government (20090076626) and the Regional Technology Innovation Program of the Ministry of Commerce, Industry and Energy (grant No. RTI04-03-03). The spectroscopic data was obtained from the Korea Basic Science Institute, Gwangju branch.

\section{References}

1. (a) Manez, R. M.; Sancenon, F. Chem. Rev. 2003, 103, 4419-4476. (b) Manez, R. M.; Sancenon, F. Journal of Fluorescene 2005, 15, 267-285.

2. (a) Gunnlaugsson, T.; Davis, A. P.; Hussey, G. M.; Tierney, J.; Glynn, M. Org. Biomol. Chem. 2004, 2, 1856-1863. (b) Gunnlaugsson, T.; Davis, A. P.; O’Brien, J. E.; Glynn, M. Org. Biomol. Chem. 2005, 3, 48-56. (c) Kim, S. K.; Singh, N. J.; Kim, S. J.; Swamy, K. M. K.; Kim, S. H.; Lee, K. H.; Kim, K. S.; Yoon, J. Tetrahedron 2005, 61, 4545-4550. (d) Kim, Y, K.; Lee, H. N.; Singh, N. J.; Choi, H. J.; Xue, J. Y.; Kim, K. S.; Yoon, J.; Hyun, M. H. J. Org. Chem. 2008, 73, 301-304. (e) Jun, E. J.; Swamy, K. M. K.; Bang, H.; Kim, S. J.; Yoon, J. Tetrahedron Lett. 2006, 47, 3103-3106. (f) Nishizawa, S.; Kaneda, H.; Uchida, T.; Teramae, N. J. Chem. Soc., Perkin Trans. 2 1998, 2325-2327. (g) Chakraborty, S.; Tarr, M. A. Can. J. Chem. 2007, 85, 153-156. (i) Liu, S. Y.; Fang, L.; He, Y. B.; Chan, W. H.; Yeung, K. T.; Cheng, Y. K.; Yang, R. H. Org. Lett. 2005, 7, 5825-5828. (j) Yen, Y. P.; Ho, K. W. Tetrahedron Lett. 2006, 47, 1193-1196. (k) Zeng, Z. Y.; He, Y. B.; Wu, J. L.; Wei, L. H.; Liu, X.; Meng, L. Z.; Yang, X. Eur. J. Org. Chem. 2004, 2888-2893. (1) Sasaki, S. I.; Citterio, D.; Ozawa, S.; Suzuki, K. J. Chem. Soc., Perkin Trans. 2 2001, 2309-2313. (m) Xie, H.; Yi, S.; Wu, S. J. Chem. Soc., Perkin Trans. 2 1999, 2751-2754.

3. (a) Kubo, Y.; Ishihara, S.; Tsukahara, M.; Tokita, S. J. Chem. Soc., Perkin Trans. 2 2002, 1455-1460. (b) Kubo, Y.; Kato, M.; Misawa, Y.; Tokita, S. Tetrahedron Lett. 2004, 45, 3769-3773. (c) Kubo, Y.; Tsukahara, M.; Ishihara, S.; Tokita, S. Chem. Commun. 2000, 653-654. (d) Nishizawa, S.; Cui, Y. Y.; Minagawa, M.; Morita, K.; Kato, Y.; Taniguchi, S.; Kato, R.; Teramae, N. J. Chem. Soc., Perkin Trans. 2 2002, 866-870. (e) Yeo, W. S.; Hong, J. I. Tetrahedron Lett. 1998, 39, 3769-3772. (f) Yeo, W. S.; Hong, J. I. Tetrahedron Lett. 1998, 39, 8137-8140.

4. For the isomerism in isothiouronium salts, see: Nguyen, Q. P. B.; Kim, J. N.; Kim, T. H. Bull. Korean Chem. Soc. 2009, 30, 20932097.

5. (a) Eftink, M. R. Methods In Enzymology 1997, 278, 221-257. (b) Cannon, W. R.; Madura, J. D.; Thummel, R. P.; McCammon, J. A. J. Am. Chem. Soc. 1993, 115, 879-884. 